\title{
Correction: Exploring the contribution of efflux on the resistance to fluoroquinolones in clinical isolates of Staphylococcus aureus
}

Sofia Santos Costa ${ }^{1,2}$, Celeste Falcão ${ }^{1}$, Miguel Viveiros ${ }^{1,3}$, Diana Machado ${ }^{1,4}$, Marta Martins ${ }^{1,4,5}$, José Melo-Cristino ${ }^{6}$, Leonard Amaral ${ }^{1,3,4}$ and Isabel Couto ${ }^{1,2^{*}}$

After the publication of our study [1], we became aware that the mutations in the quinolone resistancedetermining region (QRDR) of the gene grlA were incorrectly described for some of the Staphylococcus aureus clinical isolates studied in this work. In particular, isolates SM1, SM10, SM14, SM17, SM25, SM27, SM43, SM46, SM47 and SM48 carry the GrlA double mutation
S80Y/E84G; isolate SM52 carries the GrlA mutation S80Y; isolates SM3 and SM5 carry the GrlA double mutation S80F/E84G. The correct data can be found in Table 1.

All clinical isolates included in this study were selected upon a ciprofloxacin resistance phenotype and all the 25 representative isolates screened for mutations conferring

Table 1 Genotypic and phenotypic characterization of S. aureus clinical isolates

\begin{tabular}{|c|c|c|c|c|c|c|c|c|c|c|c|c|c|c|c|}
\hline \multirow{4}{*}{ Isolate $^{a}$} & \multirow{4}{*}{$\begin{array}{c}\text { PFGE } \\
\text { pattern }\end{array}$} & \multicolumn{2}{|c|}{ QRDR mutations ${ }^{b}$} & \multicolumn{12}{|c|}{ MIC $(\mathrm{mg} / \mathrm{L})^{\mathrm{c}}$} \\
\hline & & \multirow{3}{*}{ GrIA } & \multirow{3}{*}{ GyrA } & \multicolumn{3}{|c|}{$\mathrm{EtBr}$} & \multicolumn{3}{|c|}{ CIP } & \multicolumn{3}{|c|}{ NOR } & \multicolumn{3}{|c|}{ NAL } \\
\hline & & & & No & + & + & No & + & + & No & + & + & No & + & + \\
\hline & & & & $\mathrm{EI}$ & $\mathrm{TZ}$ & $\mathrm{CPZ}$ & $\mathrm{EI}$ & $\mathrm{TZ}$ & $\mathrm{CPZ}$ & EI & $\mathrm{TZ}$ & $\mathrm{CPZ}$ & EI & $\mathrm{TZ}$ & $\mathrm{CPZ}$ \\
\hline ATCC25923 & - & WT & WT & 6.25 & 0.75 & 0.75 & 0.25 & 0.125 & 0.125 & 0.5 & 0.125 & 0.125 & 64 & n.d. & $\overline{\text { n.d. }}$ \\
\hline ATCC25923 $\mathrm{EtBr}$ & - & WT & WT & 200 & 25 & 12.5 & 1 & 0.25 & 0.25 & 2 & 0.25 & 0.25 & 64 & n.d. & n.d. \\
\hline SM1 & $\mathrm{A} 2$ & S80Y/E84G & S84L & 16 & 4 & 4 & 128 & 32 & 64 & 512 & 128 & 256 & 256 & 64 & 64 \\
\hline SM10 & A4 & S80Y/E84G & S84L & 16 & 2 & 4 & 128 & 64 & 64 & 512 & 128 & 128 & 128 & 64 & 64 \\
\hline SM14 & A3 & S80Y/E84G & S84L & 16 & 4 & 4 & 256 & 32 & 128 & 1024 & 128 & 256 & 256 & 64 & 64 \\
\hline SM17 & A4 & S80Y/E84G & S84L & 16 & 4 & 4 & 256 & 64 & 64 & 1024 & 256 & 512 & 256 & 64 & 64 \\
\hline SM25 & $\mathrm{A} 1$ & S80Y/E84G & S84L & 8 & 2 & 4 & 128 & 32 & 64 & 512 & 64 & 128 & 256 & 32 & 64 \\
\hline SM27 & A4 & S80Y/E84G & S84L & 16 & 4 & 4 & 256 & 32 & 64 & 512 & 128 & 256 & 256 & 64 & 64 \\
\hline SM43 & $\mathrm{A} 1$ & S80Y/E84G & S84L & 16 & 2 & 4 & 128 & 64 & 64 & 512 & 128 & 128 & 512 & 256 & 64 \\
\hline SM46 & $\mathrm{A} 1$ & S80Y/E84G & S84L & 16 & 4 & 4 & 128 & 64 & 64 & 512 & 128 & 256 & 128 & 64 & 64 \\
\hline SM47 & $\mathrm{A} 1$ & S80Y/E84G & S84L & 8 & 2 & 4 & 256 & 32 & 64 & 512 & 128 & 256 & 256 & 64 & 64 \\
\hline SM48 & $\mathrm{A} 1$ & S80Y/E84G & S84L & 8 & 4 & 4 & 256 & 32 & 64 & 512 & 128 & 256 & 256 & 64 & 64 \\
\hline SM50 & B1 & S80F/E84K & S84L & 8 & 1 & 2 & 64 & 16 & 16 & 256 & 32 & 64 & 128 & 64 & 64 \\
\hline SM52 & $\mathrm{Cl}$ & S80Y & S84L & 16 & 1 & 2 & 16 & 8 & 8 & 64 & 32 & 32 & 128 & 32 & 64 \\
\hline
\end{tabular}

\footnotetext{
* Correspondence: icouto@ihmt.unl.pt

${ }^{1}$ Grupo de Micobactérias, Unidade de Microbiologia Médica, Instituto de

Higiene e Medicina Tropical, Universidade Nova de Lisboa (IHMT, UNL), Rua da Junqueira, 100, 1349-008, Lisbon, Portugal

${ }^{2}$ Centro de Recursos Microbiológicos (CREM), Faculdade de Ciências e

Tecnologia, Universidade Nova de Lisboa, Quinta da Torre, 2829-516,

Caparica, Portugal

Full list of author information is available at the end of the article
} 
Table 1 Genotypic and phenotypic characterization of S. aureus clinical isolates (Continued)

\begin{tabular}{|c|c|c|c|c|c|c|c|c|c|c|c|c|c|c|c|}
\hline SM2 & B2 & S80F/E84K & S84L & 8 & 2 & 2 & 32 & 16 & 16 & 128 & 32 & 32 & 64 & 16 & 64 \\
\hline SM3 & E1 & S80F/E84G & S84L & 1 & 1 & 1 & 16 & 8 & 8 & 64 & 32 & 32 & 64 & 16 & 16 \\
\hline SM4 & E2 & S80F & S84L & 4 & 2 & 1 & 8 & 8 & 8 & 64 & 32 & 32 & 64 & 32 & 64 \\
\hline SM5 & E3 & S80F/E84G & S84L & 4 & 2 & 1 & 32 & 16 & 16 & 128 & 64 & 64 & 64 & 32 & 32 \\
\hline SM6 & A5 & S80F & E88K & 4 & 2 & 1 & 16 & 16 & 16 & 64 & 32 & 32 & 64 & 32 & 32 \\
\hline SM7 & E1 & S80F & S84L & 2 & 2 & 1 & 8 & 8 & 4 & 64 & 32 & 32 & 128 & 32 & 64 \\
\hline SM8 & A5 & S80F & E88K & 4 & 2 & 1 & 16 & 8 & 16 & 128 & 64 & 64 & 128 & 32 & 64 \\
\hline SM12 & E1 & S80F & S84L & 2 & 2 & 1 & 16 & 8 & 8 & 64 & 32 & 32 & 128 & 32 & 64 \\
\hline SM16 & A6 & S80F & E88K & 4 & 2 & 1 & 16 & 16 & 16 & 128 & 32 & 64 & 64 & 32 & 64 \\
\hline SM22 & A1 & S80Y/E84G & S84L & 8 & 4 & 4 & 128 & 16 & 32 & 512 & 128 & 128 & 64 & 32 & 64 \\
\hline SM34 & D1 & S80F/E84K & S84L & 4 & 2 & 2 & 64 & 16 & 32 & 64 & 16 & 32 & 32 & 16 & 32 \\
\hline SM36 & E1 & S80F & S84L & 4 & 2 & 2 & 16 & 8 & 8 & 64 & 16 & 32 & 128 & 32 & 64 \\
\hline SM40 & E1 & S80F & S84L & 8 & 4 & 4 & 32 & 32 & 32 & 512 & 128 & 128 & 16 & 8 & 16 \\
\hline
\end{tabular}

asolates in bold correspond to the EtBrCW-positive isolates. ${ }^{b} \mathrm{WT}$ : wild-type; S: serine; F: phenylalanine; E: glutamate; K: lysine; Y: tyrosine; L: leucine; G: glycine. 'Values in bold-type correspond to a MIC decrease of $\geq$ four-fold in the presence of the efflux inhibitor (EI) in comparison to the values with no El [10]. The concentration of each El used is defined in the Methods section. EtBr: ethidium bromide; CIP: ciprofloxacin; NOR: norfloxacin; NAL: nalidixic acid; TZ: thioridazine; CPZ: chlorpromazine; n.d.: not determined.

fluoroquinolone resistance carried QRDR mutations in both grlA and gyrA genes. All the mutations found have been described in literature as associated with fluoroquinolone resistance in S. aureus clinical isolates [2]. As stated previously in our study, the majority of the isolates presented a double mutation in GrlA together with a single mutation in GyrA. Eleven isolates carried the GrlA and GyrA mutations S80Y/E84G and S84L, respectively; three isolates carried mutations GrlA S80F/ E84K and GyrA S84L and two isolates carried mutations GrlA S80F/E84G and GyrA S84L.The remaining nine isolates carried a single mutation in both genes, in three distinct arrangements (Table 1).

Despite this correction in the QRDR mutations carried by some of the isolates studied, the main findings of our study are not altered. In particular, our data show the potential role played by efflux systems in the development of resistance to fluoroquinolones in clinical isolates of $S$. aureus, independently of the mutations occurring in the target genes.

We apologize for any inconvenience that this may have caused to the readers.

\footnotetext{
Author details

${ }^{1}$ Grupo de Micobactérias, Unidade de Microbiologia Médica, Instituto de Higiene e Medicina Tropical, Universidade Nova de Lisboa (IHMT, UNL), Rua da Junqueira, 100, 1349-008, Lisbon, Portugal. ${ }^{2}$ Centro de Recursos Microbiológicos (CREM), Faculdade de Ciências e Tecnologia, Universidade Nova de Lisboa, Quinta da Torre, 2829-516, Caparica, Portugal. ${ }^{3}$ COST ACTION BM0701 (ATENS). ${ }^{4}$ Unidade de Parasitologia e Microbiologia Médica (UPMM), Instituto de Higiene e Medicina Tropical, Universidade Nova de Lisboa, Rua da Junqueira, 100, 1349-008, Lisbon, Portugal. ${ }^{5}$ UCD School of Public Health, Physiotherapy and Population Science, UCD Centre for Food Safety, Veterinary Sciences Centre, University College Dublin, Belfield Dublin 4, Ireland. ${ }^{6}$ Centro Hospitalar Lisboa Norte E.P.E., Instituto de Microbiologia, Instituto de Medicina Molecular, Faculdade de Medicina, Universidade de Lisboa, Avenida Professor Egas Moniz, 1649-028, Lisbon, Portugal.
}

Received: 15 May 2013 Accepted: 24 May 2013

Published: 6 June 2013

\section{References}

1. Costa SS, Falcão C, Viveiros M, Machado D, Martins M, Melo-Cristino J, Amaral L, Couto I: Exploring the contribution of efflux on the resistance to fluoroquinolones in clinical isolates of Staphylococcus aureus. BMC Microbiol 2011, 11:241.

2. Hooper DC: Mechanisms of fluoroquinolone resistance. Drug Resist Updat 1999, 2:38-55.

doi:10.1186/1471-2180-13-127

Cite this article as: Costa et al:: Correction: Exploring the contribution of efflux on the resistance to fluoroquinolones in clinical isolates of Staphylococcus aureus. BMC Microbiology 2013 13:127.

\section{Submit your next manuscript to BioMed Central and take full advantage of:}

- Convenient online submission

- Thorough peer review

- No space constraints or color figure charges

- Immediate publication on acceptance

- Inclusion in PubMed, CAS, Scopus and Google Scholar

- Research which is freely available for redistribution 